\title{
Microsatellite Analysis of 6-Hour-Old Embryos Reveals No Preferential Intraspecific Fertilization Between Cupped Oysters Crassostrea gigas and Crassostrea angulata
}

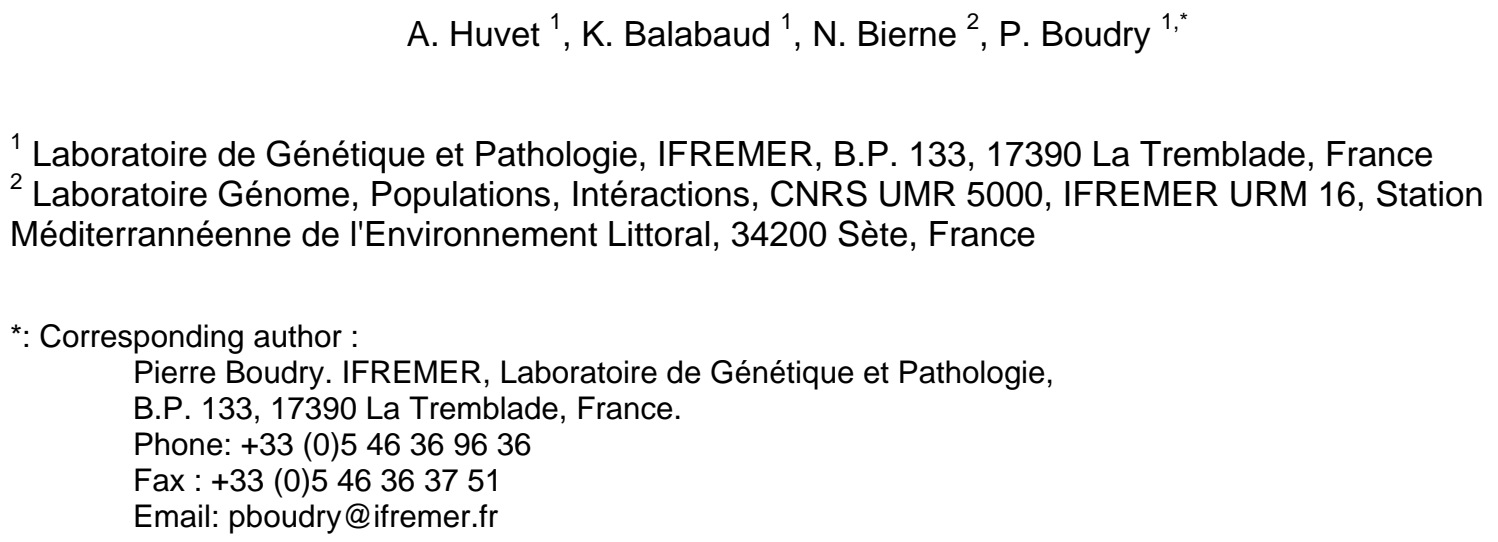

\begin{abstract}
:
Abstract: Experimental examination of reproductive isolation is the first step in understanding hybridization processes. Here, we studied preferential fertilization between 2 cupped oyster taxa, Crassostrea angulata and Crassostrea gigas, as a potential prezygotic reproductive isolation. Early examination of sperm competition is now possible by molecular analysis of oyster embryos. This avoids the confounding effect of differential mortality during the larval stage. Six hundred embryos were sampled from 2 crosses. Three microsatellite loci were enough to determine without ambiguity the taxa of contributing sires of embryos. No evidence of preferential fertilization between gametes from the same taxa was shown. A significantly higher contribution of the $\mathrm{C}$. gigas males was revealed with the $\mathrm{C}$. angulata females, but not with the $\mathrm{C}$. gigas females, which might suggest early heterosis or interaction differences between gametes. In the light of these results, natural hybridization between both taxa can be expected in cases of their geographical coexistence, as in the Southern European populations in which both taxa are in contact as a result of aquaculture development.
\end{abstract}

Keywords: Crassostrea gigas, Crassostrea angulata, hybridization, in vitro crossings, microsatellites, paternal contributions. 


\section{Introduction}

Identification of mechanisms involved in pre-zygotic reproductive isolation and their characterisation are key questions in evolutionary biology. Despite the fact that hybridisation is a common phenomenon in marine organisms (Gardner, 1997), empirical research has focused mainly on terrestrial species (reviewed by Barton and Hewitt, 1985, 1989; Harrison, 1990; Arnold, 1992). However, the life cycle of sessile marine organisms, often characterised by external fertilization, limits opportunities for pre-zygotic isolation such as behavioural mate choice. Apart from mate preferences and post-zygotic selection, the natural barriers to hybridisation should be classified into 3 other categories (Palumbi, 1994): (i) habitat specialization, (ii) spawning asynchrony and (iii) preferential fertilization, which can be viewed as a kind of assortative mating.

In the present paper, this third mechanism is investigated, studying gamete competition between two cupped oysters of commercial interest, the Pacific oyster Crassostrea gigas (Thunberg, 1793) and the Portuguese oyster Crassostrea angulata (Lamark, 1819). The main reason for their distinction into two different species, was their separated geographical distribution, $C$. angulata being present in Europe and $C$.

gigas in Asia. Based on morphological, physiological, and allozyme data (Mathers et al., 1974; Buroker et al., 1979; Mattiucci and Villani, 1983), authors concluded there was a single species divided into two sub-species (Menzel, 1974). Furthermore, all attempts to perform inter-taxa crosses were successful (reviewed by Gaffney and Allen, 1993). However, experimental cross-fertilizations were performed, as usual, without gamete competition and consequently did not enable to show differential fertilization success or assortative fertilization, that might occur in natural populations (Arnold, 
1993 ; Gregory and Howard, 1994). So the possibility of partial reproductive isolation between C. angulata and C. gigas remained to be investigated.

Unbiased quantification of sperm competition between taxa was not possible until recently due to the absence of tools which distinguished different taxa and their hybrids during early stages. Furthermore, parental contributions, assigned at juvenile stages, are the product of sperm competition and differential early mortalities (Launey and Hedgecock, 1999), potentially due to hybrid unfitness, or, on the contrary, to hybrid vigour. At the present time, we are able to conduct molecular studies with DNA extractions and PCR on individual embryos or larvae (e.g. Bierne et al., 1998) which allow the early examination of gamete competition.

In this paper, we report the study of 2 in vitro crosses with paternal taxa assignment of 6-hour-old embryos using microsatellite markers. This allows analysis of sperm competition and testing for the existence of any reproductive isolation between C. gigas and C. angulata. 


\section{Material and Methods}

\section{Crosses}

C. angulata and C. gigas oysters were sampled in Spain and France respectively. Their classification was confirmed by PCR-RFLP COI analysis as described by Boudry et al. (1998). In order to prevent any environmental effects on the gamete quality, these oysters were used as progenitors in two G0 intra-taxa crosses, and one year-old G1 progenies, reared under common conditions, were then used as progenitors for the experiment. Spermatozoa of 10 males per taxa were collected by stripping the gonad. The sperm was diluted with sea water and the concentration of spermatozoa estimated by replicates using Thoma slides coupled to an image processing system (Alcatel). Spermatozoa of each taxa were then mixed together at a balanced ratio. Ovocytes of 10 females of each taxa were collected using the same procedure, and numbered also by replicates using Mallassez slides. Ovocytes of C. gigas (cross 1) and C. angulata (cross 2) were distributed in each fertilisation beaker and were fertilised separately and simultaneously with the same 1/1 sperm pool of both taxa (ratio: 500 spermatozoa per ovocyte). G2 embryos were reared in GRP (Glass Reinforced Polyester) tanks filled with sea water (temperature $24^{\circ} \mathrm{C}$, salinity $32 \%$ ). Six hours after fertilisation, embryos were collected by sieving and preserved in $100 \%$ ethanol.

\section{Microsatellite analysis}

The parental samples (G1 progenitors) consisted of gill fragments preserved in 100\% ethanol. Six hundred embryos (G2) were placed individually into Eppendorf tubes in $20 \mu \mathrm{l}$ of $100 \%$ ethanol. This isolation of individual embryos was performed in a 
$100 \%$ ethanol drop under a microscope using a $2 \mu \mathrm{l}$ pipette. DNA extraction was performed by Chelex-based methods for adults as described by Estoup et al. (1996) and for embryos by Bierne et al. (1998). Three dinucleotide microsatellite markers (CG44, L10 and L16) were used to assess paternal contribution. Radioactive PCR amplifications and electrophoresis procedures for parental analysis were performed as described by Magoulas et al. (1998) (for CG44) and Huvet et al. (2000) (for L10 and L16). Protocols were changed in order to improve the amplifications from embryos: 40 PCR cycles were run and the denaturing temperature was decreased to $91^{\circ} \mathrm{C}$. An example of autoradiograph is presented in Figure 1.

\section{Determination of contributing paternal taxa}

For each locus, the observed parental alleles were ranked into 4 groups according to taxa (C. angulata versus $C$. gigas) and sex (female versus male). Then, we determined with certitude (by exclusion of potential sires) to which group of paternal alleles (i.e. C. angulata or C. gigas) was belonging those of each embryo. A new microsatellite locus was scored until the paternal taxa was unequivocal. This was achieved using 1 to 3 microsatellite markers. 


\section{Results}

The total number of parental microsatellite alleles was 22, 24 and 25 respectively for the CG44, L16 and L10 loci. The mean percentage of alleles shared in common between C. angulata and C. gigas parents ranged from 18.2\% (CG44), 28\% (L10) to $33.4 \%$ (L16). Over loci, $28.3 \%$ of alleles were specific to C. angulata and 45.2\% to C. gigas parents. The 4 groups of the parental alleles (i.e. according to taxa and sex) were given for each locus in Table 1 to allow determination of paternal taxa of embryos.

DNA from 373 embryos (62.2\%) was amplified. The remaining 37.8\% failed to amplify any of the three loci tested. In these cases, PCRs were repeated in order to exclude technical problems at the amplification step. This suggests that nonamplification was due to problems during earlier steps (i.e. individual sampling of embryos or DNA extraction) rather than PCR artefacts. Besides, all the genotypes observed in the progenies were compatible with the parental genotypes, excluding any contamination problems.

The determination of contributing paternal taxa of these embryos was realised by establishing to which group of paternal alleles (as defined in Table 1) was belonging those of each embryo. For example, the embryo FA10 from cross 2 ( $C$. angulata females) was genotyped 34/40 at the locus CG44 (lane h in Figure 1). Because the allele 40 was not present in the $C$. angulata dams (Table 1), the maternal allele was consequently the allele 34 . Among the 3 C. angulata females carrying the allele 34, female 5 is one a possible dam of this embryo, its genotype being genotype 25/34 (lane i in Figure 1). We can then deduce that the other allele of the embryo FA10, allele 40, 
came from C. gigas sirs, because it was not present in $C$. angulata males, and is consequently specific of $C$. gigas males (Table 1 ). Among the 3 C. gigas males carrying the allele 40 , male 6 is one a possible sir of this embryo, its genotype being 39/40 (lane w in Figure 1). So we concluded, based solely on the genotype at the locus CG44, that embryo FA10 was a hybrid.

However, for others embryos, more than one microsatellite locus was needed to determine with certitude the contributing paternal taxa. For example, the embryo FA22 from cross 2 (C. angulata females), displayed the alleles 31 and 33 at the locus CG44 (lane a in Figure 1). Because females C. angulata only showed the allele 31 (Table 1), we had to search for the allele 33 in paternal groups. Both C. angulata and C. gigas males showed commonly this allele (Table 1), it was consequently not possible to determine the paternal taxa of the embryo FA22 with the first marker. At the second locus (L10), FA22 displayed the alleles 29 and 45. Both were noticed in C. angulata females (Table 1) and the allele 29 was noticed in both male taxa. So the analysis with the third microsatellite marker L16 was needed. Alleles of FA22 were 27 and 37 at this locus. The only possible maternal allele was 37 (Table 1). Because C. angulata males showed the allele 27 and C. gigas males did not, we concluded that the contributed paternal taxa for the embryo FA22 was C. angulata.

Table 2 gives the percentage of embryos for which the paternal taxa was determined on the basis of 1,2 or 3 microsatellite loci. Assignment rate was $70.5 \%$ with the microsatellite locus CG44 alone. Adding locus L10, allowed this rate to be increase to $86 \%$. And finally, adding locus L16 allowed all the embryos from which DNA was successfully extracted to be assigned.

The contributions of $C$. angulata and $C$. gigas males when mixed together would 
be expected to produce half "pure” individuals and half of hybrids in each cross type. Pure C. gigas embryos and hybrid embryos represented respectively $56.1 \%$ and $43.9 \%$ in cross 1 (C. gigas females). In cross 2 (C. angulata females), pure C. angulata and hybrid embryos were respectively $33.7 \%$ and $66.3 \%$ (Table 3). Chi-square tests were performed in order to compare observed and expected paternal contributions. No significant deviation from the expected $1: 1$ ratio $\left(\chi^{2}=2.58\right.$; d.f.1; $\left.\mathrm{P}>0.1\right)$ was observed in cross 1 . However, in cross 2, we observed more hybrids than expected under random fertilization, this difference being statistically significant $\left(\chi^{2}=21.56\right.$; d.f. 1 ; $\left.\mathrm{P}<0.01\right)$ and significantly higher than in cross $1\left(\chi^{2}=17.69\right.$; d.f. 1 ; $\left.\mathrm{P}<0.01\right)$. 


\section{Discussion}

This molecular study on individual embryos allows the examination of gamete competition between two sub-species of cupped oysters. Three intricate steps were necessary to address the paternal contributions: the individual isolation of embryos, their DNA extraction and their analysis with microsatellite markers using PCR. The very small size of 6-hour-old embryos (mean size $=60 \mu \mathrm{m}$ ) can induce two sources of error: a bad isolation or a bad DNA extraction. The isolation of individual embryos was highly sensitive and difficult to control. So the placing of more than one embryo was possible (as seen with approximately 20 samples, impossible to assign, showing more than 2 alleles), as well as the placing of no embryo at all. Moreover, DNA extractions on such small organisms as oyster embryos cannot be always successful ( $80 \%$ on $160 \mu \mathrm{m}$ larvae in Bierne et al., 1998), and a second extraction is not possible. However, this does not introduce bias in assignment because technical artefacts at the embryo isolation step and the DNA extraction step can be considered as randomised. Furthermore, the influence of possible PCR artefacts were also ruled out by multilocus amplifications and by repeated PCR reactions.

More than two thirds of alleles are specific to parents of both taxa. Roques et al. (1999) reported similar specificity for redfish taxa (due to specific allele and/or allelic size mode). Consequently, only three microsatellite loci were enough to assign 373 embryos and the first used microsatellite (CG44) was enough to assign close to three fourth of these embryos because of its highest specificity. The relevance of microsatellite markers as molecular tools in parental assignment studies is underlined here because of their high polymorphism. (e.g. Roques et al., 1999; Norris et al., 2000; 
Gerber et al., 2000). The assignment in these studies was probabilistic whereas, in our study, we assigned the paternal taxa with certitude by exclusion of potential sires. For some embryos, several males were possible, but they always belonged to the same taxa.

Our results did not show evidence of preferential fertilization between gametes from the same cupped oyster sub-species. In cross 1 (C. gigas ovocytes), contributions were not significantly different. In contrast, in cross 2 (C. angulata ovocytes), significantly more hybrids were observed than expected. Better quality of $C$. gigas sperm is not a satisfactory explanation because, were this the case, the same discrepancies would be seen in the two crosses, and they were not $\left(\chi^{2}=17.69\right.$; d.f.1; $\mathrm{P}<0.01$ ). Results might be explained either by an early heterosis effect working in a single direction or, by heterogamy or mate choice interactions. Heterosis in F1 hybrids is a well known observation (Edmands, 1999) and it has been demonstrated to occur as early as the larval phase (Beaumont et al., 1993; Hedgecock et al., 1996). It may therefore be suggested that heterosis had occurred in cross 2 (between C. gigas males and C. angulata females) as early as during the development. Preferential interaction between $C$. angulata eggs and C. gigas sperm might be also explained by variable eggsperm interactions which are conceivable for free-spawning marine organisms (Palumbi, 1999). Indeed, ovocytes could show a non random selection of sperm from different males, that could be based on specific binding proteins (Palumbi, 1999).

Reproductive isolation explains the co-existence of sibling species in sympatry. It has been clearly documented between closely related sea urchins (e.g. Palumbi and Metz, 1991). When reproductive isolation is not achieved, the outcome of secondary contact is either (i) extinction of one of the two taxa, (ii) stable coexistence with hybridisation or (iii) reinforcement of premating isolation and speciation. The 
introduction of C. gigas into Europe (Grizel and Héral, 1991) and the present expansion of its aquaculture produced the opportunity for such a secondary contact with $C$. angulata (Huvet et al., in press). The results of the present study suggest that natural hybridization can be expected in this geographical zone. 


\section{Acknowledgements}

We thank A. Gérard for his support during the course of this work, S. Lapègue and H. McCombie for comments on the manuscript, and F. Bonhomme for helpful discussion. We thank all the staff of the IFREMER laboratory of La Tremblade for technical help with making the crosses, and F. Cornette and F. Rivet for providing oyster samples. The authors are indebted to S. Launey and F. Le Roux for their technical advice. This study was aided financially by the Conseil général of Charente-Maritime and by an IFREMER contract URM16 to LGPI. 


\section{References}

Arnold ML (1992) Natural hybridization as an evolutionary process. Annu Rev Ecol Syst, 23, 237-61

Arnold ML (1993) Rarity of hybrid formation and introgression in Louisiana irises. Plant Genetics Newsletter, 9, 14-17.

Barton NH and Hewitt GM (1985) Analysis of hybrid zones. Annu Rev Ecol Syst, 16, 113-148.

Barton NH and Hewitt GM (1989) Adaptation, speciation and hybrid zones. Nature, 341, 497-503.

Beaumont AR, Abdul-Matin AKM and Seed R (1993) Early development, survival and growth in pure and hybrid larvae of Mytilus edulis and Mytilus galloprovincialis. $J$ Moll Stud, 59, 120-123.

Bierne N, Launey S, Naciri-Graven Y and Bonhomme F (1998) Early effect of inbreeding as revealed by microsatellite analyses on Ostrea edulis larvae. Genetics, 55, 190-195.

Boudry P, Heurtebise S, Collet B, Cornette F and Gérard A (1998) Genetic differentiation between Portuguese [Crassostrea angulata (Lamark)] and Pacific [Crassostrea gigas (Thunberg)] oyster populations, as reveled by RFLP analysis of PCR amplified mitochondrial DNA segments. J Exp Mar Biol Ecol, 226, 279-291.

Buroker NE, Hershberger WK and Chew KK (1979) Populations genetics of the family Ostreidae. I. Intraspecific studies of Crassostrea gigas and Saccostrea commercialis. Mar Biol, 54, 157-169.

Edmands S (1999) Heterosis and outbreeding depression in interpopulation crosses spanning a wide range of divergence. Evolution, 53, 1757-1768. 
Estoup A, Largiader CD, Perrot E and Chourrout D (1996) Rapid one-tube extraction for reliable PCR detection of fish polymorphic markers and transgenes. Mol Mar Biol Biotechnol, 5(4), 295-598.

Gaffney PM and Allen KS (1993) Hybridization among Crassostrea species: a review. Aquaculture, 116, 1-13.

Gardner JPA (1997) Hybridization in the sea. Adv Mar Biol, 31, 1-78.

Gerber S, Mariette S, Streiff R, Bodénès C and Kremer A (2000) Comparison of microsatellites and amplified fragment length polymorphism markers for parentage analysis. Mol. Ecol., 9, 1037-1048.

Gregory PG and Howard DJ (1994) A postinsemination barrier to fertilization isolates two closely related ground crickets. Evolution, 48, 705-710.

Grizel H and Héral M (1991) Introduction into France of the Japanese oyster Crassostrea gigas. Journal du Conseil International de l'Exploration de la Mer, 47, 399-403.

Harrison RG (1990) Hybrid zones: windows on evolutionary process. Oxford Surveys in Evolutionary Biology, 7, 69-128.

Hedgecock D, McGoldrick DJ, Manahan DT, Vavra J, Appelmans N and Bayne BL (1996) Quantitative and molecular genetic analyses of heterosis in bivalve molluscs. J Exp Mar Biol Ecol, 203, 49-59.

Huvet A, Boudry P, Ohresser M, Delsert C and Bonhomme F (2000) Variable microsatellites in the pacific oyster Crassostrea gigas and other cupped oyster species. Anim Genet, 31, 71-72.

Huvet A, Lapègue S, Magoulas A and Boudry P. Mitochondrial and nuclear phylogeography of Crassostrea angulata, the Portuguese oyster endangered in 
Europe. Cons. Gen., in press.

Launey S and Hedgecock D (1999) Genetic load causes segregation distortion in oysters: mapping at 6 hours. Plant \& Animal Genome VII Conference. January 1721, 1999, San Diego, USA.

Magoulas A, Gjetvaj B, Terzoglou V and Zouros E (1998) Three polymorphic microsatellites in the Japanese oyster, Crassostrea gigas (Thunberg). Anim Genet, 29, 63-72.

Mathers NF, Wilkins NP and Walne PR (1974) Phosphoglucose isomerase and esterase phenotypes in Crassostrea angulata and C. gigas. Biochem Syst Ecol, 2, 93-96.

Mattiucci S and Villani F (1983) Studio elettroforetico dei sistemi gene-enzima in ostriche classificate come Crassostrea gigas (Thunberg, 1793) e Crassostrea angulata (Lamarck, 1819) (Mollusca: Ostreidae). Parasitologia, 25, 21-27.

Menzel RW (1974) Portuguese and Japanese oysters are the same species. J Fish Res Board Can, 31, 453-456.

Norris AT, Bradley DG and Cunningham EP (2000) Parentage and relatedness determination in farmed Atlantic salmon (Salmo salar) using microsatellite markers. Aquaculture, 182, 73-83.

Palumbi SR (1994) Genetic divergence, reproductive isolation, and marine speciation. Annu Rev Ecol Syst, 25, 547-572.

Palumbi SR (1999). All males are not created equal: fertility differences depend on gamete recognition polymorphisms in sea urchins. P.N.A.S. , 96 (22), 12632-12637.

Palumbi SR and Metz EC (1991) Strong reproductive isolation between closely related tropical sea urchins (genus Echinometra). Mol Biol Evol, 8(2), 227-239.

Roques S, Duchesne P and Bernatchez L (1999) Potential of microsatellites for 
individuals assignment: the north Atlantic redfish (genus Sebastes) species complex as a case study. Mol Ecol, 8, 1703-1717. 
Table 1. Parental microsatellite alleles grouped according taxa and sex at each microsatellite locus.

Alleles observed in the females

C. angulata Locus CG44

Locus L10

Locus L16

$9,26,32,35,37,38,41,42,43,46$

C. gigas

Locus CG44

Locus L10

$23,24,25,28,29,31,32,34$

Alleles observed in the males

26, 27, 28, 29, 32, 33, 34

9, 28, 29, 34, 35, 40, 43, 44, 47

9, 10, 27, 35, 36, 37, 39, 41, 46

29, 30, 31, 33, 34, 39, 40, 41, 45, 46

$\mathbf{1}, \mathbf{4}, \mathbf{1 9}, \mathbf{2 6}, \mathbf{2 8}, \mathbf{2 9}, \mathbf{3 0}, \mathbf{3 2}, \mathbf{3 7}, \mathbf{3 9}, 40$

Locus L16 19, 28, 29, 31, 32, 34, 38, 39, 41, 42, 46, 47, 48

In bold: specific males alleles. 
Table 2. Paternal taxa assignment of embryos using three microsatellite markers.

$$
\text { 1: CG44 2: CG44, 3 : CG44, }
$$

$\begin{array}{lll}\text { Number of loci used in the assignment } & \text { L10 } & \text { L10, L16 }\end{array}$

\% of assigned embryos for the C. gigas females

63.8

81.8

100

$\%$ of assigned embryos for the C. angulata females

77.2

89.6

100

Total \% (on both female taxa)

70.5

85.7

100 
Table 3. Taxa of contributing sires analysed on the 6-hour-old embryos.

\begin{tabular}{lccr}
\hline \multicolumn{1}{c}{ Cross } & $\begin{array}{c}\text { Number of assigned } \\
\text { embryos }\end{array}$ & $\begin{array}{c}\text { Number of embryos } \\
\text { from C. angulata father }\end{array}$ & $\begin{array}{c}\text { Number of embryos } \\
\text { from C. gigas father }\end{array}$ \\
\hline 1: C. gigas females & 171 & $75 \quad(43.9 \%)$ & $96 \quad(56.1 \%)$ \\
2: C. angulata females & 202 & $68 \quad(33.7 \%)$ & $134 \quad(66.3 \%)$ \\
\hline
\end{tabular}


Figure 1. Electrophoresis of PCR products of the microsatellite marker CG44 from a set of embryos. The individual embryos or parents are labelled from lane a to $\mathrm{z}$ in the following order : FA22, FG11, FG195, FA33, FG206, FG51, FA207, FA10, C. angulata female 5, FG184, FG37, FG127, C. angulata female 8, FG116 , FG107, FA215, C. angulata male 5, FA265, FA270, FA165, FA185, C. gigas female 3, C. gigas male 6, FG259, FA196 et FA 197 (with FG = embryo from C. gigas females (cross 1) and FA = embryo from C. angulata females (cross 2)).

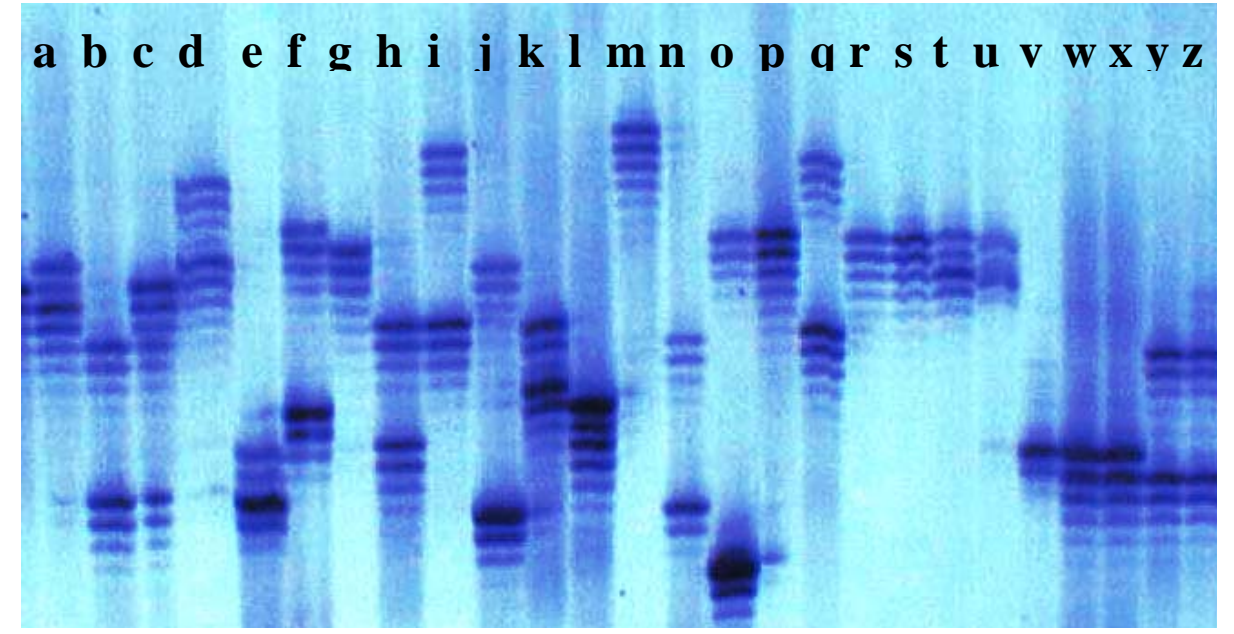

